\title{
Associations between fruit and vegetable, and antioxidant nutrient intake and age- related macular degeneration by smoking status in elderly Korean men
}

\author{
Eun-kyung Kim, Hyesook Kim, Aswathy Vijayakumar, Oran Kwon and Namsoo Chang*
}

\begin{abstract}
Background: Age-related macular degeneration (AMD) is one of the major causes of irreversible blindness. The objective of this study was to determine whether there is any relationship between dietary intake of fruits and vegetables (F\&V and antioxidant nutrients including carotenoids and AMD according to smoking status in elderly men.

Methods: We performed a cross-sectional analysis using nationally representative samples of elderly aged $\geq 65$ years $(n=1414)$ from the Korea National Health and Nutrition Examination Survey (KNHANES, 2010-2012).

Results: The current smokers consumed less food in total, and, in particular, less cereals/potatoes/sugar products, fruits and vegetables than the nonsmokers and former smokers $(p<0.05)$. Intake of energy, thiamin, vitamin $C$, vitamin $A$, and $\beta$-carotene were significantly lower in the current smokers than in the nonsmokers and the former smokers. For current smokers, the ORs of the highest tertile compared with the lowest tertile were 0.36 ( $95 \%$ Cl: $0.14-0.96, p$ for trend $=0$. 0576) for F\&V, 0.32 (95\% Cl: 0.12-0.85, p for trend $=0.0561$ ) for vitamin C, $0.23(95 \%$ Cl: 0.08-0.67, p for trend = 0.0038) for a-carotene, 0.13 ( $95 \% \mathrm{Cl}: 0.04-0.46$, $\mathrm{p}$ for trend $=0.0003$ ) for $\beta$-carotene after adjusting for confounding factors. In contrast, there was no association between antioxidant nutrient intake and AMD among the nonsmokers and former smokers.

Conclusions: These results suggest that increased consumption of fruits and vegetables containing antioxidant components such as vitamin $C$, a-carotene, and $\beta$-carotene may have a protective effect on AMD. These effects may be more evident among current smokers.
\end{abstract}

Keywords: Age-related macular degeneration, Fruit and vegetables, Antioxidants, Elderly male smokers, KNHANES

\section{Background}

Age-related macular degeneration (AMD) is one of the major causes of irreversible blindness in older adults [1]. Several studies have identified risk factors for AMD, including age [2], family history [3], diabetes mellitus [4], alcohol consumption [5], cigarette smoking [6, 7] and dietary factors [8-11].

Smoking has been reported to be the strongest environmental risk factor for AMD [7, 12]. Toxins in cigarette smoke induce cellular oxidative damage secondary to dysfunction of the biological systems that detoxify reactive oxygen species (ROS) [13] and depletion of circulating

\footnotetext{
* Correspondence: nschang@ewha.ac.kr

Department of Nutritional Science and Food Management, Ewha Womans University, Seoul 120-750, Republic of Korea
}

antioxidants [14]. In particular, oxidative stress in the retinal pigment epithelium (RPE) is a major contributing factor in the etiology of AMD [15].

Among dietary factors, fruits and vegetables [16], dairy products [17], fish [18], n-3 fatty acid [19], antioxidant vitamins $[16,19,20]$, and carotenoids, particularly $\beta$ carotene [19], lutein and zeaxanthin [21-23], are protective against AMD. Antioxidant vitamins protect cells from oxidative stress [24]. Carotenoids accumulate in the macular pigment and protect RPE cells from damage [25].

Most previous studies on the associations between diet and AMD have been conducted in Western countries, including America [26, 27], Europe [28, 29], and Australia [8, 9]. In Asia, several studies have been conducted in Japan $[19,30]$, China [31], and India [32]. Korea is expected to 
see a substantial increase in the number of elderly people in the next few decades and it has been estimated that the proportion of the population aged $\geq 60$ years will be $41.5 \%$ by 2050 [33]. Therefore, age-related health complications are becoming more important. According to the Korea National Health Examination Survey (KNHANES) report, the prevalence of smoking among Korean men was 39.3\% in 2015 [34]. In addition, Korea has the third highest number of smokers among the organization for economic cooperation and development (OECD) countries [35]. Knowledge on the epidemiology of AMD is essential to meeting future demands for eye health care and support for persons with AMD. Several studies have been carried out in an attempt to investigate the risk factors for AMD in the Korean population [2, 36]. However, the association between diet and AMD has never been studied.

Therefore, the aim of this study was to determine the relationship between $\mathrm{F} \& \mathrm{~V}$ and antioxidant nutrient intake including carotenoids and AMD by cigarette smoking status in elderly men, using data from the Korea National Health and Nutrition Examination Survey (2010-2012).

\section{Methods}

\section{Data source and study population}

This study was based on data from the fifth KNHANES (2010-2012), a cross-sectional, nationally representative survey carried out by the Korea Centers for Disease Control and Prevention. The KNHANES uses a stratified, multistage sampling method and consists of a health interview survey, a health examination survey, and a nutrition survey. The response rates for each survey were 81.9, 80.4, and $80.0 \%$ in 2010-2012, respectively. This study was approved by the Institutional Review Board of the Korea Centers for Disease Control and Prevention (2010-02CON-21-C, 201102CON-06-C, 2012-01EXP-01-2C) and written informed consent was obtained from all subjects. Detailed information about the survey is available on the website (http:// knhanes.cdc.go.kr) [37].

The study population comprised elderly men aged $\geq 65$ years who responded to the 2010-2012 KNHANES $(n=2031)$. We excluded subjects without $24 \mathrm{~h}$ dietary recall data $(n=122)$; those without fundus photograph data $(n=439)$; and those lacking smoking status data $(n=56)$. A total of 1414 participants were included in the final analysis. General characteristics of the study subjects were not significantly different between those included and excluded from the study (data not shown).

\section{Assessment of AMD}

AMD was defined as per a diagnosis by an ophthalmologist in the health examination survey. The outcome used in this study was the presence of any AMD in at least 1 eye. The presence of early- and late-onset AMD was determined on the basis of the fundus photograph [38, 39]. All fundus photographs were graded twice using the International Age related Maculopathy Epidemiological Study Group grading system [40]. Preliminary grading was performed on the site by ophthalmologist. Detailed grading was later done by nine retina specialists experienced in grading early and late AMD. The decision on any inconsistencies between the preliminary and detailed grading was done by another reading specialist. When the fundus photograph for a participant's eyes were different in severity, the grade was defined based on the more advanced grade. When the fundus photograph for only one eye was available to be assessed, the grade was evaluated by that eye. Early AMD was defined by the following criteria: the presence of soft, indistinct drusen, or reticular drusen, and the presence of distinct drusen with pigmentary abnormalities in the absence of signs of late AMD. Participants were diagnosed with late AMD if they had neovascular AMD or geographic atrophy. Neovascular AMD was defined by either the detachment of the retinal pigment epithelium (RPE) or neurosensory retina, or the presence of hemorrhages in the sub-RPE or subretinal spaces. Geographic atrophy was identified by the presence of a discrete, circular depigmented area $\geq 175 \mu \mathrm{m}$ in choroidal vessel diameter.

\section{General characteristics and smoking behavior}

The health interview survey and health examination survey were used to obtain the socio-demographic and lifestyle characteristics of the participants, such as age, body mass index (BMI), residential area, education, family income, alcohol consumption, dietary supplement use, and smoking behavior.

BMI was calculated as weight divided by height squared $\left(\mathrm{kg} / \mathrm{m}^{2}\right)$. Residential area was categorized as urban or rural. Education level was categorized as less than high school or high school and above. Family income was categorized into 4 groups according to quartile. Alcohol consumption was assessed with 5 categories (never, $\leq 1 \mathrm{drink} / \mathrm{mo}, 2-4 \mathrm{drinks} / \mathrm{mo}, 2-3$ drinks/wk., or $\geq 4$ drinks/wk. within the last year). Dietary supplement use defined as a binary variable (yes or no), included the supplementation data of the study subjects for longer than 2 weeks during the previous year. Based on smoking status, the study subjects were divided into 3 groups, nonsmokers, former smokers or current smokers.

\section{Dietary assessment and estimation of dietary intake of carotenoids}

We assessed daily dietary intake using data from a single 24-h recall form recorded in the KNAHANES. Participants reported all food and drinks consumed during the previous day in a face-to-face interview. 
The food items in this study were categorized into 9 food groups based on other previous study. The intake of foods, energy and 16 nutrients including vitamin and carotenoids were estimated. To estimate carotenoid intake, the carotenoid data was constructed based on the food items of KNHANES and the Carotenoid Content Database from the United States Department of Agriculture. A total of 2247 food items were included in the carotenoid database. The carotenoid database included $72 \%$ of all plant foods reported in the $24 \mathrm{~h}$ dietary recall method.

\section{Statistical analysis}

All statistical analyses were performed using SAS version 9.4 (SAS Institute, Cary, NC, USA). Distribution differences of the socio-demographic and lifestyle factors of the men grouped by smoking status were analyzed using the PROC SURVEYFREQ procedure. We analyzed the crude weighted mean and standard error of continuous variables by the PROC SURVEYMEAN procedure and statistical differences by smoking status were analyzed with the PROC SURVEYREG procedure. The PROC SURVEYLOGISTIC procedure was used to test our hypothesis about the relationships between fruits and vegetables, antioxidant nutrient intake, and AMD in nonsmokers and smokers. We estimated the odds ratios (ORs) and 95\% confidence intervals (CIs) for AMD across the tertiles of fruit and vegetable, vitamin $C$, vitamin $A$, and $\beta$-carotene intake, where the lowest tertile was set as the reference. Model 1 was adjusted for socio-demographic factors (age, BMI, residential area, education level, and family income). Model 2 was adjusted for the variables in model 1 plus lifestyle factors (alcohol consumption, dietary supplement use, and total energy intake) and history of diseases (diabetes mellitus and hypertension). Further, for former smokers, the data on daily smoking amount and duration of smoking was included in model 2. For the current smokers, current daily smoking amount and duration of smoking were adjusted in model 2 .

\section{Results}

\section{Characteristics of the study population}

The subjects' age, prevalence of AMD, residential area, dietary supplement use, and diabetes mellitus did not differ by smoking status (Table 1). However, the current smokers had lower BMI, educational status and lower family income than the nonsmokers and the former smokers. The ratio of subjects who had higher intake of alcohol was higher among current smokers than the nonsmokers and the former smokers. The ratio of subjects with hypertension was higher among former smokers than the nonsmokers and the current smokers. The subjects included in this study did not differ from excluded subjects in terms of their general characteristics (data not shown).

The current smokers consumed less food in total, and, in particular, less cereals/potatoes/sugar products, fruits and vegetables than did the nonsmokers and the former smokers (Table 2). Intake of energy, thiamin, vitamin $\mathrm{C}$, vitamin $A$, and $\beta$-carotene were significantly lower in the current smokers than in the nonsmokers and the former smokers.

\section{Relationship of F\&V and antioxidant nutrient intake and smoking status with AMD}

We further evaluated the relationship in separate smoking status (Table 3). As expected, for the current smokers, AMD was inversely associated with F\&V [OR $(95 \% \mathrm{CI})=$ $0.36(0.14-0.96)$, $\mathrm{p}$ for trend $=0.0576]$, vitamin $\mathrm{C}$ [OR $(95 \%$ $\mathrm{CI})=0.32(0.12-0.85), \mathrm{p}$ for trend $=0.0561], \alpha$-carotene [OR $(95 \% \mathrm{CI})=0.23(0.08-0.67)$, p for trend $=0.0038$ ] and $\beta$-carotene $[\mathrm{OR}(95 \% \mathrm{CI})=0.13(0.04-0.46), \mathrm{p}$ for trend $=$ 0.0003 ] intake after adjusted for confounding factors. For nonsmokers and former smokers, however, there was no association between intake of fruits and vegetables and antioxidant nutrients and AMD.

\section{Discussion}

We found significant inverse associations between F\&V and antioxidant nutrient intake and AMD in smokers. The highest tertiles of $F \& V$, vitamin $C, \alpha$-carotene, and $\beta$-carotene intake were associated with significantly reduced odds ratios for AMD compared to the lowest tertiles. In contrast, no statistically significant associations were observed in nonsmokers.

We found that smokers consumed significantly less fruits and vegetables, and antioxidant nutrients, which is consistent with previous studies [41-44]. In this study, F\&V intake was $23.3 \%$ lower in the current smokers $(444.0 \mathrm{~g} / \mathrm{d})$ than in the nonsmokers $(578.7 \mathrm{~g} / \mathrm{d})$. In the Food Habits of Canadians Survey, in adults aged 18-65 years, male smokers showed reduced intake of fruits and vegetables (4.0 servings/d vs. 5.6 servings/d) in comparison with nonsmokers [41]. In a national population-based cohort study conducted in the US, subjects in the highest quartile of fruit and vegetable consumption (29.62 times/week) were more likely to quit smoking and less likely to be heavy smokers than were those in the lowest quartile [42]. The China Seven Cities Study (CSCS) observed that smokers were $46-60 \%$ less likely to consume fruit at least once a day than were those who had never smoked [43].

Unlike in other studies [8, 16], no statistically significant associations were observed in nonsmokers and AMD. We found inverse associations between F\&V and AMD in current smokers only. Several studies reported that high fruit and vegetable intake is inversely associated with AMD [8, 16]. A cross-sectional study conducted in 
Table 1 Characteristics of participants by smoking status ${ }^{a}$

\begin{tabular}{|c|c|c|c|c|}
\hline Variables & Nonsmokers $(n=227)$ & Former smokers $(n=856)$ & Current smokers $(n=331)$ & $p$-value \\
\hline Age (y) & $71.6 \pm 0.4$ & $72.1 \pm 0.2$ & $71.3 \pm 0.3$ & 0.1433 \\
\hline BMI $\left(\mathrm{kg} / \mathrm{m}^{2}\right)$ & $23.6 \pm 0.2$ & $23.4 \pm 0.1$ & $22.7 \pm 0.2$ & 0.0009 \\
\hline AMD & $35(12.5)$ & $115(14.5)$ & $56(18.0)$ & 0.3052 \\
\hline \multicolumn{5}{|l|}{ Residential area } \\
\hline Urban & $154(66.0)$ & $588(67.5)$ & $207(62.3)$ & \multirow[t]{2}{*}{0.3489} \\
\hline Rural & $73(34.0)$ & $268(32.5)$ & $124(37.7)$ & \\
\hline \multicolumn{5}{|l|}{ Education } \\
\hline Less than high school & $127(57.3)$ & $509(64.0)$ & $241(74.9)$ & \multirow[t]{2}{*}{0.0005} \\
\hline High school and above & $99(42.7)$ & $347(36.0)$ & $90(25.1)$ & \\
\hline \multicolumn{5}{|l|}{ Family income } \\
\hline$<25$ th & $88(36.1)$ & $373(44.4)$ & $182(54.1)$ & \multirow[t]{4}{*}{0.0113} \\
\hline 25th to 50 th & $76(38.2)$ & $251(29.9)$ & $76(22.7)$ & \\
\hline 50th to 75 th & $38(16.3)$ & $129(13.8)$ & $40(13.4)$ & \\
\hline 75th to 100th & $24(9.4)$ & $96(11.8)$ & $30(9.8)$ & \\
\hline \multicolumn{5}{|l|}{ Alcohol consumption } \\
\hline Never & $88(40.2)$ & $281(32.1)$ & $83(25.1)$ & \multirow[t]{5}{*}{0.0007} \\
\hline$\leq 1 \mathrm{mo}$ & $41(19.1)$ & $162(19.6)$ & $51(15.6)$ & \\
\hline $2-4 / \mathrm{mo}$ & $42(17.6)$ & $138(15.1)$ & $52(16.0)$ & \\
\hline $2-3 / w k$ & $35(14.4)$ & $124(14.6)$ & $56(16.6)$ & \\
\hline$\geq 4 w k$ & $20(8.7)$ & $148(18.7)$ & $89(26.7)$ & \\
\hline \multicolumn{5}{|l|}{ Dietary supplement use } \\
\hline Yes & $89(36.1)$ & $373(42.2)$ & $113(34.4)$ & 0.0940 \\
\hline Diabetes mellitus & $35(15.0)$ & $162(18.2)$ & $68(19.3)$ & 0.5096 \\
\hline Hypertension & $98(42.2)$ & $438(52.4)$ & $129(40.2)$ & 0.0028 \\
\hline \multicolumn{5}{|l|}{ Smoking behavior } \\
\hline Daily smoking amount of former smokers (n/d) & - & $29.8 \pm 1.2$ & - & - \\
\hline Duration of former smoking $(y)$ & - & $18.3 \pm 0.5$ & - & - \\
\hline Daily smoking amount of current smokers ( $\mathrm{n} / \mathrm{d}$ ) & - & - & $13.8 \pm 0.5$ & - \\
\hline Duration of smoking $(y)$ & - & - & $49.5 \pm 0.5$ & - \\
\hline
\end{tabular}

Data availability was limited in the following categories: age $(n=1414)$; BMI $(n=1414)$; residential area $(n=1414)$; education $(n=1413)$; family income $(n=1403)$; alcohol consumption $(n=1410)$; dietary supplement use $(n=1414)$; diabetes mellitus $(n=1414)$; hypertension $(n=1414)$; daily smoking amount of former smokers ( $n=852)$; duration of former smoking $(n=855)$; daily smoking amount $(n=331)$; duration of smoking $(n=331)$

$B M I$ body mass index, $A M D$ age related macular degeneration

${ }^{a}$ Values are mean \pm s.e. or $n(\%) ; n=1414$

Australia showed that the proportion of individuals who met the recommended daily intake of vegetables was lower amongst patients with late-stage AMD than in a population of age- and sex-matched controls with no signs of AMD (52.9\% vs. $64.5 \%, p=0.0002)$ [8]. Recent studies have assessed the associations between healthy dietary patterns, including high fruit and vegetable consumption, and AMD $[45,46]$. In the Carotenoids in Age-Related Eye Disease Study (CAREDS), which used the Healthy Eating Index (HEI), subjects whose HEI scores were ranked in the highest quintile (median serving of 3.1 for fruits and 4.6 for vegetables) had a $46 \%$ lower risk of early-stage AMD compared to those in the lowest quintile (median serving of 1.5 for fruits and 3.0 for vegetables) [45]. In our study, the mean intake of fruits and vegetables was $578.7 \mathrm{~g} / \mathrm{d}$ among nonsmokers, which is higher than what is observed in other elderly male populations (Chinese: $313.0 \mathrm{~g} / \mathrm{d}$ [47], Malaysian: 2.51 svg/d [48], Swedish: 3.3 svg/d [49], American: 3.38 svg/d [50]). Furthermore, the prevalence of hypertension (52.4\%), one of the risk factors for AMD, was higher in our study population compared to other study (35.6\%) [51]. We presume that in our study, among Korean elderly male nonsmokers other risk factor for AMD will be more meaningful than intake of fruits and vegetables. 
Table 2 Daily foods and nutrients intake by smoking status

\begin{tabular}{|c|c|c|c|c|c|}
\hline & \multirow{2}{*}{$\begin{array}{l}\text { Nonsmokers } \\
(n=227)\end{array}$} & \multirow{2}{*}{$\begin{array}{l}\text { Former smokers } \\
(n=856)\end{array}$} & \multirow{2}{*}{$\begin{array}{l}\text { Current smokers } \\
(n=331)\end{array}$} & \multicolumn{2}{|l|}{$p$-value } \\
\hline & & & & Model $1^{a}$ & Model $2^{b}$ \\
\hline \multicolumn{6}{|l|}{ Foods } \\
\hline Total foods (g) & $1368.4 \pm 62.0$ & $1318.9 \pm 31.7$ & $1262.5 \pm 47.2$ & 0.2051 & 0.0049 \\
\hline Cereals/potatoes/sugar products (g) & $401.5 \pm 14.6$ & $374.3 \pm 7.7$ & $358.2 \pm 8.8$ & 0.0128 & 0.0298 \\
\hline Beans/nuts/seeds (g) & $41.6 \pm 6.2$ & $45.9 \pm 3.0$ & $35.6 \pm 3.9$ & 0.2132 & 0.1571 \\
\hline Meats and eggs (g) & $70.7 \pm 7.4$ & $73.5 \pm 5.3$ & $80.9 \pm 9.4$ & 0.5601 & 0.3160 \\
\hline Fishes and shellfishes (g) & $39.9 \pm 4.9$ & $47.1 \pm 3.5$ & $49.5 \pm 5.1$ & 0.3195 & 0.5066 \\
\hline Milk and dairy products (g) & $48.3 \pm 8.3$ & $49.6 \pm 4.7$ & $35.8 \pm 6.5$ & 0.5836 & 0.6781 \\
\hline Fruits and vegetables (g) & $578.7 \pm 43.4$ & $524.6 \pm 19.2$ & $444.0 \pm 27.4$ & 0.0020 & 0.0035 \\
\hline Fruits (g) & $204.6 \pm 32.8$ & $156.0 \pm 12.7$ & $125.2 \pm 23.4$ & 0.0570 & 0.1301 \\
\hline Vegetables (g) & $374.1 \pm 22.5$ & $368.7 \pm 12.4$ & $318.8 \pm 12.6$ & 0.0113 & 0.0062 \\
\hline Mushrooms (g) & $4.6 \pm 3.1$ & $5.3 \pm 1.7$ & $1.5 \pm 0.6$ & 0.1014 & 0.1070 \\
\hline Seaweeds (g) & $4.4 \pm 1.1$ & $5.1 \pm 0.7$ & $5.4 \pm 1.9$ & 0.8381 & 0.8973 \\
\hline \multicolumn{6}{|l|}{ Nutrients } \\
\hline Energy (kcal) & $2032.9 \pm 67.7$ & $1935.6 \pm 36.1$ & $1995.7 \pm 47.5$ & 0.5190 & $<.0001$ \\
\hline Carbohydrate (g) & $363.9 \pm 12.2$ & $340.8 \pm 6.7$ & $334.7 \pm 7.6$ & 0.0944 & 0.1450 \\
\hline Protein (g) & $66.4 \pm 2.5$ & $63.6 \pm 1.4$ & $62.3 \pm 2.0$ & 0.6056 & 0.2334 \\
\hline Fat (g) & $31.2 \pm 2.0$ & $29.0 \pm 1.1$ & $27.1 \pm 1.4$ & 0.4352 & 0.2659 \\
\hline Calcium (mg) & $480.6 \pm 23.9$ & $496.4 \pm 14.2$ & $448.0 \pm 19.2$ & 0.1844 & 0.0732 \\
\hline Phosphorus (mg) & $1228.6 \pm 45.6$ & $1134.1 \pm 20.9$ & $1108.8 \pm 30.0$ & 0.1332 & 0.1443 \\
\hline Iron (mg) & $17.8 \pm 2.0$ & $15.1 \pm 0.5$ & $14.4 \pm 0.7$ & 0.2512 & 0.2554 \\
\hline Thiamin (mg) & $1.4 \pm 0.1$ & $1.2 \pm 0.0$ & $1.2 \pm 0.0$ & 0.0522 & 0.0078 \\
\hline Riboflavin (mg) & $1.1 \pm 0.1$ & $1.1 \pm 0.0$ & $1.0 \pm 0.0$ & 0.1723 & 0.1122 \\
\hline Niacin (mg) & $15.9 \pm 0.5$ & $15.5 \pm 0.4$ & $15.3 \pm 0.5$ & 0.8700 & 0.2463 \\
\hline Vitamin C (mg) & $105.6 \pm 7.1$ & $97.8 \pm 3.4$ & $78.7 \pm 4.3$ & 0.0003 & 0.0011 \\
\hline Vitamin A ( $\mu g R E)$ & $729.2 \pm 54.2$ & $700.6 \pm 28.0$ & $601.1 \pm 42.0$ & 0.1100 & 0.0760 \\
\hline a-carotene (mg) & $1.0 \pm 0.2$ & $0.8 \pm 0.1$ & $0.7 \pm 0.1$ & 0.1044 & 0.1323 \\
\hline$\beta$-carotene (mg) & $4.9 \pm 0.4$ & $4.6 \pm 0.2$ & $3.6 \pm 0.3$ & 0.0148 & 0.0245 \\
\hline$\beta$-cryptoxanthin (mg) & $0.6 \pm 0.2$ & $0.4 \pm 0.0$ & $0.4 \pm 0.1$ & 0.6031 & 0.7048 \\
\hline Lutein + zeaxanthin (mg) & $2.9 \pm 0.3$ & $2.5 \pm 0.2$ & $2.4 \pm 0.2$ & 0.3354 & 0.5297 \\
\hline Lycopene (mg) & $1.1 \pm 0.3$ & $1.3 \pm 0.2$ & $0.7 \pm 0.2$ & 0.0695 & 0.0755 \\
\hline
\end{tabular}

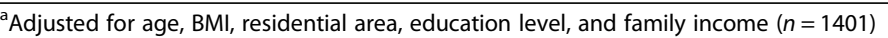

${ }^{\mathrm{b}}$ Adjusted for age, BMI, residential area, education level, family income, alcohol consumption, dietary supplement use, diabetes mellitus, and hypertension, and total energy intake $(n=1397)$

We also observed a significant inverse relationship between intake of antioxidant nutrients such as vitamin $C$, $\alpha$-carotene, and $\beta$-carotene and AMD among current smokers. Major dietary sources of $\beta$-carotene include green leafy vegetables and yellow fruits and vegetables such as spinach, carrots, pumpkin, and sweet potato [52]. There has been no observational study showing the relationship of dietary intake and smoking with AMD. However, some experimental studies have shown the protective effects of micronutrients derived from fruits and vegetables, such as vitamin A (particularly $\beta$ carotene), vitamin $\mathrm{C}$, vitamin $\mathrm{E}$, folic acid, and phenolic compounds, against smoke-induced toxicity, via prevention of lipid peroxidation [53, 54]. Cigarette smoking causes a depletion of intrinsic antioxidant capacity and thus promotes lipid oxidation [53]. Cigarette smokeinduced free radical generation may be the first step in lipid peroxidation in the membrane of LDL particles. That is, lipid peroxidation of LDL may begin after depletion of intrinsic antioxidants such as vitamin $\mathrm{E}$ ( $\alpha$-tocopherol) and $\beta$-carotene [53]. These nutrients act as antioxidants, as they have the ability to scavenge free radicals and prevent membrane lipid peroxidation [53]. Hininger et al. reported in an intervention study, which involved increased 
Table 3 Odds Ratios (95\% Cls) for AMD according to dietary intake in nonsmokers and smokers

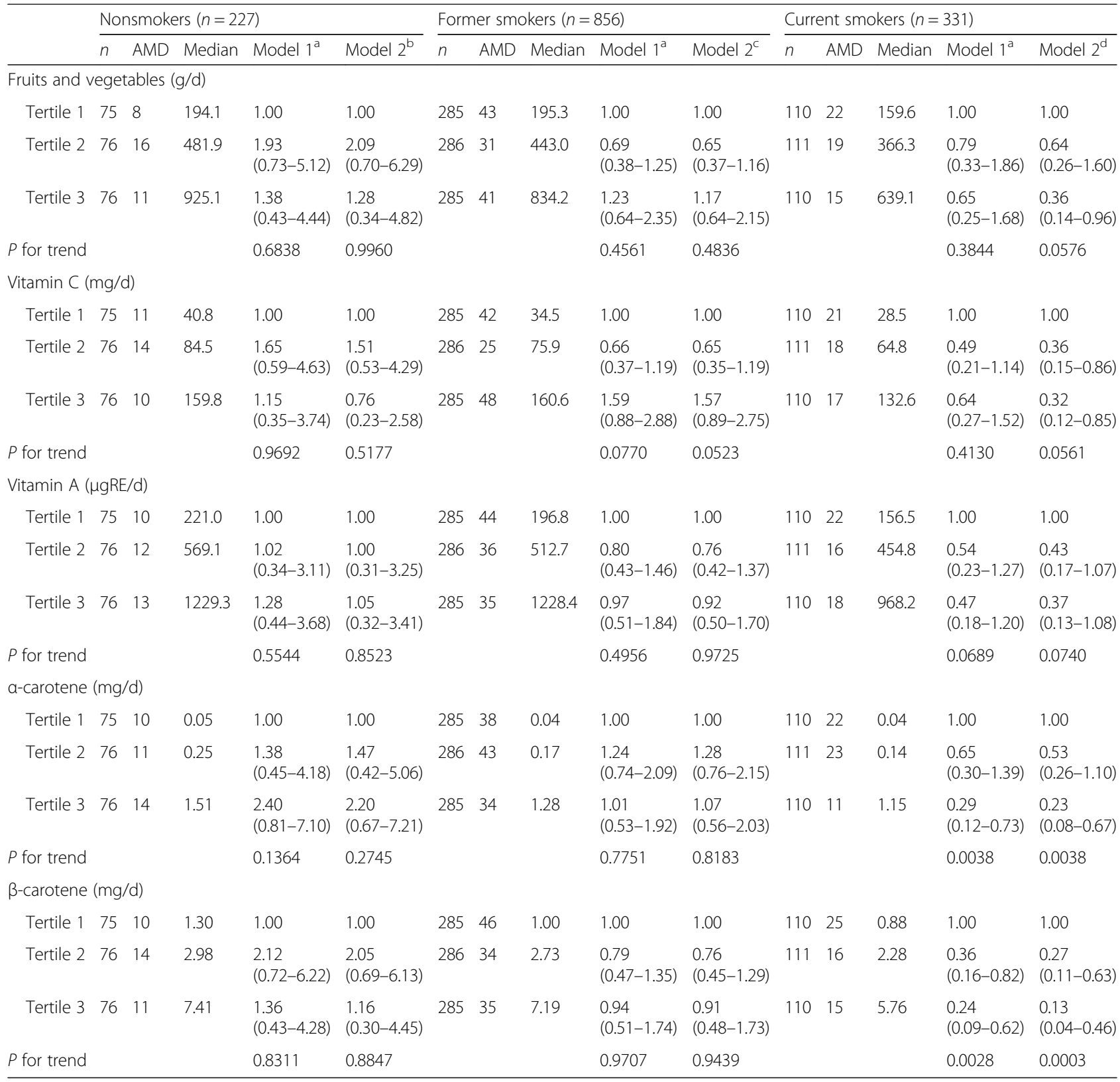

$A M D$ age related macular degeneration, $B M I$ body mass index

${ }^{\mathrm{a}}$ Model 1 adjusted for age, BMI, residential area, education level, and family income

${ }^{b}$ Model 2 adjusted for age, BMI, residential area, education level, family income, alcohol consumption, dietary supplement use, and total energy intake

${ }^{c}$ Model 2 adjusted for age, BMI, residential area, education level, family income, alcohol consumption, dietary supplement use, total energy intake, daily smoking

amount of former smokers, and duration of former smoking

${ }^{\mathrm{d}}$ Model 2 adjusted for age, BMI, residential area, education level, family income, alcohol consumption, dietary supplement use, total energy intake, daily smoking

amount of current smokers, and duration of smoking

fruit and vegetable consumption for two weeks providing additional $30 \mathrm{mg} /$ day of carotenoids (10 mg $\beta$-carotene, $10 \mathrm{mg}$ lycopene and $10 \mathrm{mg}$ lutein) per day, that serum carotene concentrations in smokers are more susceptible to fluctuate compared to nonsmokers from the intervention study [55]. We presume that these mechanisms account for the clearer effect of high F\&V consumption and high antioxidant intake among smokers.
We observed the extreme low values in OR for prevalence of AMD across the tertiles of $\beta$-carotene intake among smokers. This may be due to the relatively small number of subjects in the smoking-subgroups. A previous cross-sectional population-based study using the data from the National Health and Nutrition Examination Survey (NHANES) also found that subjects in the highest quintile category of carotenoid intake (lutein/zeaxanthin) had a 
90\% lower risk for AMD compared with those in the lowest quintile category [OR $(95 \% \mathrm{CI})=0.1(0.0-0.9)]$ [56].

In our study, the smokers consumed fewer milk and dairy products and calcium than the nonsmokers. Although we did not observe any association between milk and dairy product intake and AMD, one recent study reported a significant linear trend, over a 15 -year period between consumption of dairy foods and the incidence of late AMD [17]. Further research is needed to confirm these results.

The prevalence of AMD did not differ by smoking status in the current study. However, smoking strongly affect the onset and progression of AMD [7, 57]. Coleman et al. reported that, after 15-year of follow-up, the ORs for early-stage AMD among nonsmokers and smokers aged $\geq 80$ years were 1.63 and 5.49 , respectively, in comparison to nonsmokers aged $<80$ years [58]. Cigarette smoke causes oxidative damage directly and indirectly. Toxins in smoke cause damage directly by generating a large number of free radicals [59] and indirectly by depleting endogenous circulating antioxidants [14].

This study has several limitations. First, the KNHANES is a cross-sectional study, so we cannot explain the causal relationship between dietary nutrient intake and AMD. Second, our dietary data was derived from a single 24-h dietary recall survey, which may provide an inaccurate estimate of normal diet. However, according to the KNHANES report, variations in data from a single day and 2-10 days of 24-h dietary recall were not much different $(3.9 \%$ for energy, $14.2 \%$ for vitamin $\mathrm{A}$, and $7.8 \%$ for fiber) [60]. Furthermore, the difference $(30.3 \%)$ in vitamin A intake between nonsmokers and smokers is much greater than the withinperson variation for vitamin A intake. Third, we examined only dietary intake of antioxidant nutrients, but not dietary supplement intake. We analyzed only the intakes of vitamin $\mathrm{A}$ and vitamin $\mathrm{C}$ from dietary supplements. There was no significant difference for vitamin $\mathrm{A}$ and $\mathrm{C}$ from dietary supplements according to smoking status (vitamin A: $292.8 \pm$ 161.6 for nonsmokers, $153.2 \pm 31.7$ for former smokers, and $89.2 \pm 41.6$ for current smokers; vitamin C: $121.5 \pm 32.8$ for nonsmokers, $137.2 \pm 20.1$ for former smokers, and 93.5 \pm 29.8 for current smokers). However, we have limited data on nutrient intakes from dietary supplements [515 subjects (36.4\%)] and these data were available for 2010 and 2011 years, but not 2012. Therefore, we were unable to estimate nutrient intakes from foods and supplements.

Nevertheless, to the best of our knowledge, this is the first study to find that the AMD prevalence among cigarette smokers is inversely associated with consumption of $F \& V$ and antioxidant nutrients. This observation implies that future studies investigating the protective effect of fruit and vegetable consumption on AMD should consider smoking status. We estimated the association between $\beta$-carotene intake and AMD. Several studies have observed associations between carotenoids, particularly lutein/zeaxanthin, and AMD [26, 27, 56]. Thus, further studies are needed to elucidate this relationship between antioxidant nutrients and AMD.

\section{Conclusions}

In conclusion, we found that intake of fruits and vegetables, vitamin $C, \alpha$-carotene, and $\beta$-carotene may protect against AMD in elderly male smokers. Future studies are warranted to explore the mechanisms related to the beneficial role of fruits and vegetables and antioxidant nutrients against AMD in smokers. The current results also suggest that public health interventions for elderly smokers should focus on improving dietary habits, including increasing fruit and vegetable consumption, as well as on smoking cessation.

\section{Abbreviations}

AMD: Age-related macular degeneration; CAREDS: Carotenoids in AgeRelated Eye Disease Study; CSCS: China Seven Cities Study; F\&V: Fruits and vegetables; HEl: Healthy Eating Index; KNHANES: Korea National Health and Nutrition Examination Survey; NHANES: National Health and Nutrition Examination Survey; OECD: Organization for economic cooperation and development; ROS: Reactive oxygen species; RPE: Retinal pigment epithelium

\section{Acknowledgements}

Not applicable

Funding

This research was supported by the Brain Korea 21 Plus.

Availability of data and materials

Detailed information about the survey is available on the website (http:// knhanes.cdc.go.kr).

\section{Authors' contributions}

EK analyzed the data and wrote the manuscript; HK interpreted data and revised the manuscript; $A V$ revised the manuscript; OK constructed the carotenoid database; NC designed the research. All the authors read and approved the final manuscript.

\section{Ethics approval and consent to participate}

This study was approved by the Institutional Review Board of the Korea Centers for Disease Control and Prevention (2010-02CON-21-C, 2011-02CON06-C, 2012-01EXP-01-2C) and written informed consent was obtained from all subjects.

\section{Consent for publication}

Not applicable

\section{Competing interests}

The authors declare that they have no competing interests.

\section{Publisher's Note}

Springer Nature remains neutral with regard to jurisdictional claims in published maps and institutional affiliations.

Received: 30 May 2017 Accepted: 27 November 2017

Published online: 04 December 2017

References

1. Foran S, Wang JJ, Mitchell P. Causes of visual impairment in two older population cross-sections: the Blue Mountains eye study. Ophthalmic Epidemiol. 2003;10:215-25.

2. Cho BJ, Heo JW, Kim TW, Ahn J, Chung H. Prevalence and risk factors of age-related macular degeneration in Korea: the Korea National 
Health and nutrition examination survey 2010-2011. Invest Ophthalmo Vis Sci. 2014;55:1101-8.

3. Shahid H, Khan JC, Cipriani V, Sepp T, Matharu BK, Bunce C, Harding SP, Clayton DG, Moore AT, Yates JR. Age-related macular degeneration: the importance of family history as a risk factor. $\mathrm{Br} J$ Ophthalmol. 2012;96:427-31.

4. Cho BJ, Heo JW, Shin JP, Ahn J, Kim TW, Chung H. Epidemiological association between systemic diseases and age-related macular degeneration: the Korea National Health and nutrition examination survey 2008-2011. Invest Ophthalmol Vis Sci. 2014;55:4430-7.

5. Piermarocchi S, Tognetto D, Piermarocchi R, Masetto M, Monterosso G, Segato T, Cavarzeran F, Turrini A, Peto T. Risk factors and age-related macular degeneration in a Mediterranean-Basin population: the PAMDI (prevalence of age-related macular degeneration in Italy) study - report 2. Ophthalmic Res. 2016;55:111-8.

6. Myers $C E$, Klein $B E$, Gangnon R, Sivakumaran $T A$, lyengar SK, Klein R. Cigarette smoking and the natural history of age-related macular degeneration: the beaver dam eye study. Ophthalmology. 2014;121: 1949-55.

7. Woodell A, Rohrer B. A mechanistic review of cigarette smoke and agerelated macular degeneration. In: Retinal degenerative diseases. Advances in experimental medicine and biology (Volume 801). New York: Springer; 2014. p. 301-7.

8. Gopinath B, Liew G, Russell J, Cosatto V, Burlutsky G, Mitchell P. Intake of key micronutrients and food groups in patients with late-stage age-related macular degeneration compared with age-sex-matched controls. Br J Ophthalmol. 2017;101(8):1027-31.

9. Amirul Islam FM, Chong EW, Hodge AM, Guymer RH, Aung KZ, Makeyeva GA, Baird PN, Hopper JL, English DR, Giles GG, Robman LD. Dietary patterns and their associations with age-related macular degeneration: the Melbourne collaborative cohort study. Ophthalmology. 2014;121:1428-34. e1422

10. Koushan K, Rusovici R, Li W, Ferguson LR, Chalam KV. The role of lutein in eye-related disease. Nutrients. 2013;5:1823-39.

11. Schleicher M, Weikel K, Garber C, Taylor A. Diminishing risk for agerelated macular degeneration with nutrition: a current view. Nutrients. 2013;5:2405-56.

12. Smith W, Assink J, Klein R, Mitchell P, Klaver CC, Klein BE, Hofman A Jensen S, Wang JJ, de Jong PT. Risk factors for age-related macular degeneration: pooled findings from three continents. Ophthalmology. 2001;108:697-704

13. Jarrett SG, Boulton ME. Consequences of oxidative stress in age-related macular degeneration. Mol Asp Med. 2012;33:399-417.

14. Moriarty SE, Shah JH, Lynn M, Jiang S, Openo K, Jones DP, Sternberg P. Oxidation of glutathione and cysteine in human plasma associated with smoking. Free Radic Biol Med. 2003;35:1582-8.

15. Ozawa Y. Oxidative stress in the RPE and its contribution to AMD pathogenesis: implication of light exposure. In: Neuroprotection and Neuroregeneration for retinal diseases. Japan: Springer; 2014. p. 239-53.

16. Cho E, Seddon JM, Rosner B, Willett WC, Hankinson SE. Prospective study of intake of fruits, vegetables, vitamins, and carotenoids and risk of age-related maculopathy. Arch Ophthalmol. 2004;122:883-92.

17. Gopinath B, Flood VM, Louie JC, Wang JJ, Burlutsky G, Rochtchina E, Mitchell P. Consumption of dairy products and the 15-year incidence of age-related macular degeneration. Br J Nutr. 2014;111:1673-9.

18. Zhu W, Wu Y, Meng YF, Xing Q, Tao JJ, Lu J. Fish consumption and agerelated macular degeneration incidence: a meta-analysis and systematic review of prospective cohort studies. Nutrients. 2016;8(11):e743.

19. Aoki A, Inoue M, Nguyen E, Obata R, Kadonosono K, Shinkai S, Hashimoto H, Sasaki S, Yanagi Y. Dietary n-3 fatty acid, alpha-tocopherol, zinc, vitamin D, vitamin $\mathrm{C}$, and beta-carotene are associated with age-related macular degeneration in Japan. Sci Rep. 2016;6:20723.

20. Evans JR, Lawrenson JG. Antioxidant vitamin and mineral supplements for slowing the progression of age-related macular degeneration. Cochrane Database Syst Rev. 2012;11:Cd000254

21. Ma L, Yan SF, Huang YM, XR L, Qian F, Pang HL, XR X, Zou ZY, Dong PC, Xiao $X$, et al. Effect of lutein and zeaxanthin on macular pigment and visual function in patients with early age-related macular degeneration. Ophthalmology. 2012;119:2290-7.

22. Krinsky NI, Landrum JT, Bone RA. Biologic mechanisms of the protective role of lutein and zeaxanthin in the eye. Annu Rev Nutr. 2003;23:171-201.
23. Eisenhauer B, Natoli S, Liew G, Flood VM. Lutein and Zeaxanthin-Food sources, bioavailability and dietary variety in age-related macular degeneration protection. Nutrients. 2017;9(2):e120.

24. Pisoschi AM, Pop A. The role of antioxidants in the chemistry of oxidative stress: a review. Eur J Med Chem. 2015;97:55-74.

25. Chichili GR, Nohr D, Frank J, Flaccus A, Fraser PD, Enfissi EM, Biesalski HK. Protective effects of tomato extract with elevated beta-carotene levels on oxidative stress in ARPE-19 cells. Br J Nutr. 2006;96:643-9.

26. Wu J, Cho E, Willett WC, Sastry SM, Schaumberg DA. Intakes of lutein, zeaxanthin, and other carotenoids and age-related macular degeneration during 2 decades of prospective follow-up. JAMA Ophthalmol. 2015;133:1415-24.

27. Chew EY, Clemons TE, Sangiovanni JP, Danis RP, Ferris FL 3rd, Elman MJ, Antoszyk AN, Ruby AJ, Orth D, Bressler SB, et al. Secondary analyses of the effects of lutein/zeaxanthin on age-related macular degeneration progression: AREDS2 report no. 3. JAMA Ophthalmol. 2014;132:142-9.

28. Kaarniranta K, Machalinska A, Vereb Z, Salminen A, Petrovski G, Kauppinen A. Estrogen signalling in the pathogenesis of age-related macular degeneration. Curr Eye Res. 2015;40:226-33.

29. Beatty S, Koh H, Phil M, Henson D, Boulton M. The role of oxidative stress in the pathogenesis of age-related macular degeneration. Surv Ophthalmol. 2000:45:115-34.

30. Michikawa T, Ishida S, Nishiwaki Y, Kikuchi Y, Tsuboi T, Hosoda K, Ishigami A, Iwasawa S, Nakano M, Takebayashi T. Serum antioxidants and age-related macular degeneration among older Japanese. Asia Pac J Clin Nutr. 2009;18:1-7.

31. Yao Y, Qiu QH, XW W, Cai ZY, Xu S, Liang XQ. Lutein supplementation improves visual performance in Chinese drivers: 1-year randomized, doubleblind, placebo-controlled study. Nutrition. 2013;29:958-64.

32. Nidhi B, Mamatha BS, Padmaprabhu CA, Pallavi P, Vallikannan B. Dietary and lifestyle risk factors associated with age-related macular degeneration: a hospital based study. Indian J Ophthalmol. 2013;61:722-7.

33. Kellen E, Zeegers M, Paulussen A, Van Dongen M, Buntinx F. Fruit consumption reduces the effect of smoking on bladder cancer risk. The Belgian case control study on bladder cancer. Int J Cancer. 2006;1 18:2572-8.

34. Korea Centers for Disease Control and Prevention. In: Ministry oHaW, editor. Korea National Health and Nutrition Examination Survey 2015 (KNHANES VI3). Seoul: Korea Centers for Disease Control and Prevention; 2016

35. How's Life? 2015 Measuring Well-being [http://www.oecd-ilibrary.org/ content/graph/how_life-2015-graph61-en].

36. Park SJ, Lee JH, Woo SJ, Ahn J, Shin JP, Song SJ, Kang SW, Park KH. Agerelated macular degeneration: prevalence and risk factors from Korean National Health and nutrition examination survey, 2008 through 2011. Ophthalmology. 2014;121:1756-65.

37. Korea Centers for Disease Control and Prevention. In: Ministry oHaW, editor. The Fifth Korea National Health and Nutrition Examination Survey (KNHANES V). Seoul: Korea Centers for Disease Control and Prevention; 2013.

38. Yoon K-C, Mun G-H, Kim S-D, Kim S-H, Kim CY, Park KH, Park YJ, Baek S-H, Song SJ, Shin JP, et al. Prevalence of eye diseases in South Korea: data from the Korea national health and nutrition examination survey 2008-2009. Korean J Ophthalmol. 2011;25:421-33.

39. Cho BJ, Heo JW, Shin JP, Ahn J, Kim TW, Chung H. Association between reproductive factors and age-related macular degeneration in postmenopausal women: the Korea National Health and nutrition examination survey 2010-2012. PLoS One. 2014;9:e102816.

40. Bird AC, Bressler NM, Bressler SB, Chisholm IH, Coscas G, Davis MD, de Jong PT, Klaver CC, Klein BE, Klein R, et al. An international classification and grading system for age-related maculopathy and age-related macular degeneration. The international ARM epidemiological study group. Surv Ophthalmol. 1995;39:367-74.

41. Palaniappan U, Jacobs Starkey L, O'Loughlin J, Gray-Donald K. Fruit and vegetable consumption is lower and saturated fat intake is higher among Canadians reporting smoking. J Nutr. 2001;131:1952-8.

42. Haibach JP, Homish GG, Giovino GA. A longitudinal evaluation of fruit and vegetable consumption and cigarette smoking. Nicotine Tob Res. 2013;15:355-63.

43. Masood S, Cappelli C, Li Y, Tanenbaum H, Chou CP, Spruijt-Metz D, Palmer $\mathrm{PH}$, Johnson CA, Xie B. Cigarette smoking is associated with unhealthy patterns of food consumption, physical activity, sleep impairment, and alcohol drinking in Chinese male adults. Int J Public Health. 2015;60:891-9. 
44. Endoh K, Kuriki K, Kasezawa N, Tohyama K, Goda T. Association between smoking status and food and nutrient consumption in Japanese: a largescale cross-sectional study. Asian Pac J Cancer Prev. 2015;16:6527-34.

45. Mares JA, Voland RP, Sondel SA, Millen AE, Larowe T, Moeller SM, Klein ML, Blodi BA, Chappell RJ, Tinker L, et al. Healthy lifestyles related to subsequent prevalence of age-related macular degeneration. Arch Ophthalmol. 2011;129:470-80.

46. Merle BM, Silver RE, Rosner B, Seddon JM. Adherence to a Mediterranean diet, genetic susceptibility, and progression to advanced macular degeneration: a prospective cohort study. Am J Clin Nutr. 2015;102:1196-206.

47. Xie H-L, B-H W, Xue W-Q, He M-G, Fan F, Ouyang W-F, S-I T, Zhu H-L, Chen Y-M. Greater intake of fruit and vegetables is associated with a lower risk of osteoporotic hip fractures in elderly Chinese: a 1: 1 matched case-control study. Osteoporos Int. 2013;24:2827-36.

48. Cheong S, Jasvindar K, Lim K, Surthahar A, Ambigga D. Prevalence and factors influencing fruit and vegetable consumption among Malaysian elderly. Int J Public Health Clin Sci. 2017;4:28-39.

49. Benetou V, Orfanos P, Feskanich D, Michaëlsson K, Pettersson-Kymmer U, Eriksson S, Grodstein F, Wolk A, Bellavia A, Ahmed LA. Fruit and vegetable intake and hip fracture incidence in older men and women: the CHANCES project. J Bone Miner Res. 2016:31:1743-52.

50. Sharkey JR, Johnson CM, Dean WR. Food access and perceptions of the community and household food environment as correlates of fruit and vegetable intake among rural seniors. BMC Geriatr. 2010;10:32.

51. Hyman L, Schachat AP, He Q, Leske MC. Hypertension, cardiovascular disease, and age-related macular degeneration. Age-related macular degeneration risk factors study group. Arch Ophthalmol. 2000;118:351-8.

52. Barbosa-Filho JM, Alencar AA, Nunes XP, Tomaz AC, Sena-Filho JG, AthaydeFilho PF, Silva MS, Souza MF, Da-Cunha EVL. Sources of alpha-, beta-, gamma-, delta-and epsilon-carotenes: a twentieth century review. Rev Bras. 2008;18:135-54.

53. Diana JN. Tobacco smoking and nutrition. Ann N Y Acad Sci. 1993;686:1-11.

54. Frei B. Ascorbic acid protects lipids in human plasma and low-density lipoprotein against oxidative damage. Am J Clin Nutr. 1991;54:1113s-8s.

55. Hininger I, Chopra M, Thurnham DI, Laporte F, Richard MJ, Favier A, Roussel AM. Effect of increased fruit and vegetable intake on the susceptibility of lipoprotein to oxidation in smokers. Eur J Clin Nutr. 1997;51:601-6.

56. Mares-Perlman JA, Fisher Al, Klein R, Palta M, Block G, Millen AE, Wright JD. Lutein and zeaxanthin in the diet and serum and their relation to agerelated maculopathy in the third national health and nutrition examination survey. Am J Epidemiol. 2001;153:424-32.

57. Thornton J, Edwards R, Mitchell P, Harrison RA, Buchan I, Kelly SP. Smoking and age-related macular degeneration: a review of association. Eye (Lond). 2005;19:935-44.

58. Coleman AL, Seitzman RL, Cummings SR, Yu F, Cauley JA, Ensrud KE, Stone KL, Hochberg MC, Pedula KL, Thomas EL, Mangione CM. The association of smoking and alcohol use with age-related macular degeneration in the oldest old: the study of osteoporotic fractures. Am J Ophthalmol. 2010;149:160-9.

59. Church DF, Pryor WA. Free-radical chemistry of cigarette smoke and its toxicological implications. Environ Health Perspect. 1985;64:111-26.

60. Korea MoHaWo. In: Prevention KCfDCa, editor. Report presentation of Korea National Health and Nutrition Examination Survey IV, 2009. Osong: Korea Centers for Disease Control and Prevention; 2010.

\section{Submit your next manuscript to BioMed Central and we will help you at every step:}

- We accept pre-submission inquiries

- Our selector tool helps you to find the most relevant journal

- We provide round the clock customer support

- Convenient online submission

- Thorough peer review

- Inclusion in PubMed and all major indexing services

- Maximum visibility for your research

Submit your manuscript at www.biomedcentral.com/submit 